\title{
Eficácia da vitamina D na prevenção e tratamento da Covid-19
}

\author{
Effectiveness of vitamin D in the prevention and treatment of Covid-19 \\ Eficacia de la vitamina D en la prevención y tratamiento del Covid-19
}

Recebido: 21/09/2021 | Revisado: 28/09/2021 | Aceito: 30/09/2021 | Publicado: 03/10/2021

\author{
Patrício Oliveira Ferraz Santos \\ ORCID: https://orcid.org/0000-0003-4504-8756 \\ Faculdade Independente do Nordeste, Brasil \\ E-mail: patriciooliveiraferraz@gmail.com \\ Flávio Mendes de Souza \\ ORCID: https://orcid.org/0000-0002-6296-7159 \\ Faculdade Independente do Nordeste, Brasil \\ E-mail: flaviomendes@fainor.com.br
}

\begin{abstract}
Resumo
O sistema imunitário, inato e adaptativo, é uma rede altamente evoluída e complexa, é essencial para promover a sobrevivência em um ambiente com potenciais agentes patogênicos, enquanto mantem a tolerância. Agora é bem estabelecido que a vitamina $\mathrm{D}$ desempenha um papel proeminente na saúde imunitária, além dos seus efeitos clássicos. Não é surpreendente que a insuficiência e deficiência de vitamina $\mathrm{D}$ parecem aumentar a suscetibilidade às infecções bacterianas e virais. Insuficiência e deficiência de vitamina D estão aumentando globalmente e podem ser atribuídos às mudanças na dieta e no comportamento. Estudos epidemiológicos também apontam uma relação entre a vitamina D e a COVID-19. Esta revisão avalia criticamente os aspectos genéticos, epidemiológicos, artigos e estudos para desvendar o papel e o modo de ação da vitamina D nas perturbações do sistema imunológico, associando também seu uso na prevenção e tratamento da COVID-19.
\end{abstract}

Palavras-chave: Vitamina D; Covid-19; Insuficiência.

\begin{abstract}
The immune system, innate and adaptive, is a highly evolved and complex network, it is essential for promoting survival in an environment with potential pathogens, while maintaining tolerance. It is now well established that vitamin D plays a prominent role in immune health, in addition to its classic effects. Not surprisingly, vitamin D insufficiency and deficiency appear to increase susceptibility to bacterial and viral infections. vitamin D insufficiency and deficiency are increasing globally and can be attributed to changes in diet and behavior. Epidemiological studies also point to a relationship between vitamin D and COVID-19. This review critically evaluates the genetic, epidemiological, articles and studies to unravel the role and mode of action of vitamin D in immune system disorders, also linking its use in the prevention and treatment of COVID-19.
\end{abstract}

Keywords: Vitamin D; Covid-19; Insufficiency.

\section{Resumen}

El sistema inmunológico innato y adaptativo, una red compleja y altamente evolucionada, es esencial para promover la supervivencia en un entorno con patógenos potenciales, mientras se mantiene la tolerancia. Ahora está bien establecido que la vitamina D juega un papel destacado en la salud inmunológica además de sus efectos clásicos. No es sorprendente que la insuficiencia y la deficiencia de vitamina D parezcan aumentar la susceptibilidad a las infecciones bacterianas y virales. La insuficiencia y la deficiencia de vitamina D están aumentando a nivel mundial y pueden atribuirse a cambios en la dieta y el comportamiento. Los estudios epidemiológicos también apuntan a una relación entre la vitamina D y COVID-19. Esta revisión evalúa críticamente los artículos y estudios genéticos, epidemiológicos para desentrañar el papel y el modo de acción de la vitamina D en los trastornos del sistema inmunológico, asociando también su uso en la prevención y el tratamiento de COVID-19.

Palabras clave: Vitamina D; Covid-19; Insuficiencia.

\section{Introdução}

Essa revisão tem como perspectiva analisar a controvérsia em torno da definição de deficiência e insuficiência de vitamina $\mathrm{D}$, além de fornecer orientações sobre como tratar e prevenir a deficiência de vitamina $\mathrm{D}$, auxiliando no tratamento e prevenção da covid-19. 
A deficiência e insuficiência de vitamina D é um problema global de saúde, que afeta mais de um bilhão de crianças e adultos ao redor do mundo. As consequências da deficiência da vitamina D não podem ser estimadas. Tem ocorrido uma associação da deficiência de vitamina D com algumas doenças agudas e crônicas, entre elas a desordem do sistema autoimune, doenças infecciosas, câncer, diabetes e desordens neurológicas (Van Schoor, NM. 2011).

A atual -pandemiall de deficiência de vitamina D chocou com a pandemia da COVID- 19 e acredita-se que aumentou drasticamente o número de mortes, decorrente da insuficiência de vitamina D. Embora não existam atualmente estudos controlados que demonstrem a presença de vitamina D na eficácia contra a COVID-19, há muitos estudos deste tipo em curso. Os estudos observacionais sobre vitamina D recebeu uma atenção considerável, visto que existe um vasto conjunto de publicações que relatam a associações entre o estado de vitamina $\mathrm{D}$ e múltiplas doenças, incluindo a COVID-19. O interesse na promoção da saúde nos efeitos da vitamina D aumentou substancialmente durante o século XXI. Há aproximadamente 5.000 artigos referentes à vitamina D ligados à revista US National, biblioteca utilizada como base de dados de Medicina nos últimos cinco anos (Chakhtoura, M. 2020).

Até ao século XXI, a vitamina D era reconhecida principalmente pelo seu papel na regulação do cálcio, saúde óssea e a prevenção do raquitismo. Nos últimos 20 anos, no entanto, a investigação mostrou que a vitamina $\mathrm{D}$ também tem profundas influências nas células imunitárias e causa uma diminuição da inflamação. É um poderoso regulador epigenético que influencia mais de 2.500 genes, e com impacto em dezenas dos nossos mais sérios desafios de saúde, como as doenças cardíacas e o cancro, doenças autoimunes como a Esclerose Múltipla, entre outras. (Brown, R. 2020).

A vitamina D é uma molécula produzida a partir do precursor direto do colesterol, que está normalmente presente na pele utilizando a energia fornecida pela UV-B componente da luz solar numa reação que não requer qualquer assistência enzimática. Na sua via clássica, a vitamina D é convertida para sua forma única hidroxi (25-hidroxivitamina D) no seu fígado e depois à sua dupla forma hidroxi (1,25-dihidroxivitamina $\mathrm{D})$ nos seus rins e até nas suas células imunitárias que atuam no combate a infecções. (Cashman, KD. 2016).

A vitamina D é diferente da maioria das vitaminas, na medida em que o seu corpo pode produzi-la por si só com exposição à luz solar, por se um metabolito primário é considerado como um hormônio esteróidal. Ao contrário da maioria das vitaminas, que atuam como antioxidantes ou cofatores enzimáticos, a forma 1,25( $\mathrm{OH}) 2 \mathrm{D}$ da vitamina $\mathrm{D}$ funciona através da ligação do receptor de vitamina D que está presente na membrana celular, ou no núcleo. Uma vez que a vitamina D ativa o receptor, torna-se um regulador principal da função celular (Chibuzor, MT. 2020).

\subsection{Problema}

A vitamina D é eficaz para a prevenção e/ou tratamento da COVID-19?

\subsection{Hipótese}

Vitamina D é eficaz para a prevenção e/ou tratamento da COVID-19. Vitamina D não é eficaz para a prevenção e/ou tratamento da COVID-19.

\subsection{Justificativa}

Devido ao grande número de artigos que foram publicados nos últimos meses, que reforçam o uso da vitamina $\mathrm{D}$, além de buscar entender e propagar uma forma segura de auxiliar a população que se encontra à mercê da situação pandêmica atual. 


\subsection{Objetivos}

\section{Objetivo geral}

Analisar através de uma revisão da literatura nos últimos anos a eficácia da Vitamina D na prevenção e/ou tratamento da COVID-19.

\section{Objetivos específicos}

O objetivo desta pesquisa de revisão da literatura é ajudar a compreender porque é tão importante melhorar os níveis de vitamina D no organismo, a fim de garantir funções imunitárias saudáveis, e depois apresentar estratégias de como realizar de forma adequada, portanto analisar a ação da vitamina D na atuação do reforço no sistema imunológico de forma geral, prevenindo a infecção do vírus da COVID-19.

\subsection{Referencial teórico}

A vitamina D ou colecalciferol, apesar de ser denominada vitamina, trata-se conceitualmente de um pré-hormônio, por não ser produzido por uma glândula endócrina não se trata de um hormônio clássico. Juntamente com o paratormônio, atuam como importantes reguladores na homeostase do cálcio e no metabolismo ósseo (MAEDA, et al., 2014).

A exposição à luz solar fornece para a maioria das pessoas o requerimento necessário de vitamina D. Em idosos, a capacidade de sintetizar vitamina $\mathrm{D}$ pela exposição à luz solar encontra-se diminuída, em decorrência de a pele do idoso perder progressivamente sua eficiência de síntese de vitamina D. Logo, concentrações diminuídas de vitamina D são mais recorrentes nessa população, fato que pode ser agravado pela menor exposição solar, comum em idosos (HOLICK, et al., 2008).

Alguns estudos correlacionaram a ingestão alimentar de vitamina D e a prevalência de doenças autoimunes, artrite as reumatoides e diabetes mellitus tipo 1 , no entanto, a avaliação correta da ingestão de vitamina $\mathrm{D}$ é desafiadora, pois é baseada na memória do paciente. Para contornar a medição desafiadora da ingestão de vitamina D e exposição ao sol, os níveis no soro podem ser úteis e, de fato, os níveis baixos de $25(\mathrm{OH}) \mathrm{D} 3$ no soro de pacientes afetados por doenças autoimunes em relação a controles saudáveis têm foi encontrado. No entanto, esses estudos demonstraram uma correlação e não uma relação causal (SADEGHIAN, et al., 2016).

Além de doenças autoimunes, a vitamina D também tem sido implicada no controle de outras condições inflamatórias, como doenças cardiovasculares: em modelos animais, a administração de vitamina D3 reduz a produção de citocinas próinflamatórias pelos macrófagos e diminui a aterosclerose e a inflamação no tecido adiposo epicárdico (GUNASEKAR, et al., 2018).

O sistema imunológico inato é a primeira defesa contra a infecção, ele é necessário para lutar rapidamente contra patógenos invasores. O sistema imunológico inato compreende componente tanto do hospedeiro quanto dos micróbios residentes (HOLICK, et al., 2008).

A defesa do hospedeiro compreende barreiras físicas à infecção (como pele, superfícies mucosas, muco e células endoteliais vasculares), enzimas expressas por células epiteliais e fagocíticas, peptídeos e proteínas antimicrobianas, componentes inflamatórios e receptores celulares que reconhecem rapidamente patógenos e componentes (AMREIN, et al.,2014).

O sistema imunológico adaptativo ou sistema imunológico adquirido é a segunda defesa contra a infecção. Ele é necessário para lutar especificamente contra patógenos, é ativado pela exposição a patógeno e, ao contrário, o sistema imunológico inato é capaz de aprender sobre o patógeno e aumentar a resposta imunológica de acordo, graças a uma memória imunológica. O sistema imune adaptativo é composto por células T e B e também é responsável pela reação autoimune (WEI, et al., 2015). 
No quadro de doenças infecciosas, o objetivo do sistema imunológico é reconhecer a invasão de patógenos, impedir a sua propagação e eliminá-los do seu corpo. Esse extraordinário complexo sistema depende de milhões de células que vigiam o corpo e de uma rede complexa e dinâmica (ROBB, et al., 2016).

Para ajudá-lo a compreender o impacto da vitamina D no seu sistema imunológico, é primeiro importante compreender alguns elementos fundamentais do seu sistema imunológico inato e adaptativo. O seu sistema imunitário compreende dois tipos de imunidades diferentes, mas que atuam em conjunto: inata e adaptativa (ROBB. CT, et al., 2016).

A sua imunidade inata age em poucas horas após um agente patogênico estranho, enquanto a sua imunidade adaptativa leva alguns dias para reagir, mas fornece imunidade em longo prazo, normalmente vitalícia a uma infecção (ROBN. CT, et al., 2016).

O sistema imunológico inato é a primeira linha de defesa do organismo contra infecções, e agem rapidamente contra agentes patogênicos invasores. Responde de uma forma genérica, sem conferir uma forma duradoura e imunidade específica (Vanherwegen, et al., 2017).

O sistema imunológico inato estabelece barreiras físicas, como a pele, as células que revestem o intestino e vasos sanguíneos, existe também barreiras químicas como saliva e ácido estomacal. Estas barreiras ajudam para bloquear a entrada de organismos causadores de doenças no corpo (Vanherwegen, et al., 2017).

Ao contrário das respostas imunitárias adaptativas, as respostas imunitárias inatas são sempre gerais, não são específicas de um determinado agente patogênico e dependem de um grupo de células e proteínas que reconhecem características conservadas de micróbios que rapidamente promovem a depuração de agentes infecciosos (CACERE, et al., 2012).

O sistema imunológico inato estabelece barreiras físicas, como a pele, as células que revestem o intestino e vasos sanguíneos, existe também barreiras químicas como saliva e ácido estomacal. Estas barreiras ajudam para bloquear a entrada de organismos causadores de doenças no corpo (Cacere, et al., 2012).

A vitamina D é conhecida como regulador de uma porção da barreira física do seu sistema imunológico inato e é responsável por melhorar as células epiteliais que revestem o intestino. Também modula o sistema imunológico do intestino. Baixos níveis de vitamina D irão aumentar a sua permeabilidade intestinal e permitir a infiltração de agentes patogênicos na sua corrente sanguínea causando inflamações de baixo grau (Vanherwegen, et al., 2017).

Os glóbulos brancos também fazem parte do seu sistema imunitário inato e servem como a iniciativa primária de defensores contra agentes patogênicos no seu corpo. Os neutrófilos são mais abundantes nas células brancas e contribuem para a sua primeira linha de defesa contra os agentes patogênicos (Vanherwegen, et al., 2017).

Os neutrófilos podem eliminar micróbios através de um processo chamado fagocitose, ou simplesmente digerindo-os dentro dos seus glóbulos brancos onde é exposto a espécies reativas de oxigênio, que são gerados em resposta aos agentes patogênicos, o que leva ainda mais à produção de moléculas antimicrobianas (Vanherwegen, et al., 2017).

As células dendríticas desempenham um papel fundamental nas respostas imunitárias inatas e adaptativas. Uma vez que são as células com maior presença de antígeno, estimulam de forma eficaz a ativação de linfócitos T e B, combinando assim a imunidade inata e adaptativa (Vanherwegen, et al., 2017).

As células dendríticas pesquisam permanentemente o seu corpo e são especializadas na absorção de antígenos de agentes patogênicos. Ao serem expostos a sinais inflamatórios, amadurecem e migram para a sua linfa e apresentam os seus antígenos capturados às células T, gerando assim uma resposta imunitária adaptativa (Vanherwegen, et al., 2017).

Os macrófagos são outro tipo de glóbulos brancos que se juntam à primeira linha da defesa inata contra agentes patogênicos e são importantes para engolir bactérias, como fazem os glóbulos brancos, mas também em produzir e secretar uma série de proteínas advindas da sinalização inflamatória e anti-inflamatória (Vanherwegen, et al., 2017). 
O sistema imunológico adaptativo é composto principalmente pelos seus linfócitos T e B. Em comparação com a imunidade inata, a imunidade adaptativa é mais lenta para começar, mas forte o suficiente para completar a eliminação das infecções que escapam da sua imunidade inata. A imunidade adaptativa é descrita melhor pela sua especificidade aos antígenos estranhos e a sua capacidade de gerar uma memória imunitária duradoura (Cacere, et al., 2012).

A ativação do sistema imune adaptativo começa normalmente com a apresentação do antígeno por células inatas a células $\mathrm{T}$ ajudantes, o que leva à sua interação com células $\mathrm{B}$ ingénuas. Ajudando na ativação e diferenciação delas em memória e células secretoras B que produzem os anticorpos para protegê-lo de futuras infecções (Cacere, et al., 2012).

As células T, células T CD4+e células T CD8+ desempenham um papel antiviral significativo ao equilibrar o combate contra agentes patogênicos e o risco de desenvolvimento de autoimunidade ou inflamações (CACERE, et al., 2012).

As células T CD4+ promovem a produção de anticorpos específicos do vírus através da ativação das células $\mathrm{T}$ dependente de células B. No entanto, as células T CD8+ são tóxicas para agentes patogênicos e podem matar células infectadas por vírus. Células T CD8+ representam cerca de $80 \%$ do total de células inflamatórias nos pulmões de doentes infectados com corona vírus e desempenham um papel vital na eliminação do vírus nas células infectadas e na indução de lesões imunitárias. (Maloir, et al., 2018).

A ativação de células T CD4+ ingénuas gera diferentes classes de células T ajudantes, que diferem de acordo com o tipo de resposta imunitária que produzem. Assim, as células auxiliares $\mathrm{T}$ do tipo 1 ajudam na imunidade mediada por células, enquanto que a resposta das células $\mathrm{T}$ de tipo 2 ajudam na resposta humoral (Lang, et al., 2017).

As citocinas são pequenas proteínas secretadas pelas células do sistema imune inato e adaptativo. Servem para regularem diversas funções na resposta imunológica. As citocinas são liberadas por células na circulação ou diretamente nos tecidos. As citocinas localizam as células imunitárias alvo e interage com os receptores das células imunes alvo ligando-se a elas. Essa interação desencadeia e estimula respostas específicas por parte das células-alvo (LI, et al., 2020).

Em resposta a infeções bacterianas e virais, como a COVID-19, o sistema imune inato gera tanto citocinas próinflamatórias como anti-inflamatórias. A resposta inflamatória desempenha um papel crucial nas manifestações clínicas da COVID-19. O SARS-CoV-2 desencadeia uma resposta contra o vírus, que se não for controlada, pode resultar em danos pulmonares, deficiência funcional e capacidade pulmonar reduzida (Mcgonagle, et al., 2020)

A inflamação viral relacionada com a SARS-CoV-2 e a subsequente tempestade de citocinas em casos graves desempenha um papel crucial na sobrevivência dos pacientes. A liberação excessiva e descontrolada de citocinas próinflamatórias é conhecida como tempestade de citocinas. Clinicamente, a tempestade de citocinas é comum e apresenta-se como uma inflamação sistêmica e falência de múltiplos órgãos (Xu, et al., 2020).

As citocinas inflamatórias que controlam essa resposta são TNF $\alpha$ e Interleucinas, são produzidas na fase inicial da resposta imune inata ao vírus. Essas citocinas, entre outras, contribuem para o recrutamento e ativação das células da resposta imune adaptativa (Gruber-bzura, et al., 2018).

Há uma investigação convincente que demonstra que a vitamina D pode melhorar a estabilidade endotelial mesmo em tempestades de citocinas. Isso pode ocorrer devido ao papel da vitamina D na modulação das células T ajudantes e produção de citocinas, mas também através da promoção de células reguladoras $\mathrm{T}$, que são responsáveis pela ação anti-infecciosa, para suprimir respostas imunes e limitar o processo de inflamação (Bruce, et al., 2015).

A vitamina $\mathrm{D}$ ajuda a diminuir a regulação das respostas imunes controladas pelas células $\mathrm{T}$ ajudantes, assim inibindo a produção de citocinas pró-inflamatórias, tais como interferon gamma tipo 1 e Inter leucinas como IL-6, IL-2, juntamente com o fator de necrose tumoral alfa (TNF- $\alpha$ ) (Sharifi, et al., 2019).

Foi bem estabelecido que a deficiência de vitamina D melhora a tempestade de citocinas. Isso ocorre porque a vitamina D modula a sua imunidade adaptativa e suprime as respostas, auxiliado pelas células $\mathrm{T}$ auxiliares, reprimindo a 
produção de citocinas inflamatórias como $\mathrm{TNF} \alpha$ e Interleucinas como IL-2 e interferon gamma. Além disso, a vitamina D promove estímulos à produção das células T reguladoras que inibem os processos inflamatórios (Jeffery, et al., 2009).

Parece haver um enorme valor da vitamina D nas infecções por COVID-19, como a sua administração reduz a expressão dessas citocinas pró-inflamatórias e aumenta a expressão de citocinas anti-inflamatórias por macrófagos. Foi demonstrada que a vitamina $\mathrm{D}$ regula as respostas inflamatórias, alterando o equilíbrio pró-inflamatório/anti-inflamatório em direção a um equilíbrio anti-inflamatório estado inflamatório que controla a explosão inflamatória uma vez desencadeada (Gombart, et al., 2020).

Estudos de cultura celular mostraram que a vitamina D diminui a expressão de citocinas pró-inflamatório, aumenta a produção de proteínas antivirais e também tem eficácia antiviral, especialmente confrontado com vírus envelopados; consequentemente, provavelmente seria eficaz contra os envelopados SARS-CoV-2 que ocasiona a COVID-19 (LOEB, et al., 2019).

Como prova adicional de que a vitamina $\mathrm{D}$ reduz a inflamação, um estudo recente mostrou uma forte correlação com níveis de vitamina $\mathrm{D}$ e proteína $\mathrm{C}$ reativa (CRP). Dado que a CRP é um marcador substituto para tempestade de citocinas, que apoia o papel da vitamina $\mathrm{D}$ na redução de complicações atribuídas a inflamação não regulada devido à tempestade de citocinas causada pela COVID-19 (Daneshkha, et al., 2020).

\section{Metodologia}

\subsection{Tipos de Estudos}

Trata-se de uma revisão sistemática de literatura a elaboração de uma questão de pesquisa orientadora da estratégia de busca, variedade de fontes para a localização dos estudos, definição de critérios de inclusão, exclusão e avaliação da qualidade metodológica das produções recuperadas (Berwanger, et al., 2007).

O trabalho desenvolvido seguirá os preceitos de uma revisão sistemática de literatura, por meio de uma pesquisa bibliográfica, desenvolvida a partir de material já elaborado, constituído de livros e artigos científicos.

\subsection{Fonte de Dados}

Foram incluídos somente trabalhos com foco específico na vitamina D e estudos com delineamento do tipo casocontrole, cujos dados tivessem sido avaliados e comparados antes eapós a intervenção, visando garantir o fato de possíveis mudanças verificáveis no tema. Não houve restrição quanto à data de publicação, apenas em relação ao idioma de divulgação dos trabalhos, sendo incluídos apenas aqueles disponibilizados em português e inglês.

Fontes que forneceram as respostas adequadas à solução do problema proposto:

a) Artigos científicos sobre a temática foram acessados nas bases de dados Scielo, BDENF, LILACS, MEDLINE, publicados nos últimos anos.

b) Para a seleção das fontes, foram consideradas como critério de inclusão as bibliografias que abordassem a vitamina $\mathrm{D}$ e consequentemente a temática, e foram excluídas aquelas que não atenderam a temática.

A coleta de dados seguiu a seguinte ideia:

a) Leitura Sistemática de todo o material selecionado.

b) Leitura Seletiva.

c) Registro das informações extraídas das fontes. 


\subsection{Análise de Dados}

Foram realizadas leituras analíticas com a finalidade de organizar as informações encontradas nas fontes, de forma que possibilitassem a obtenção de respostas ao problema da pesquisa, analisar e discutir a partir do referencial teórico relativo à temática do estudo.

\section{Resultados e Discussão}

É esperado que com os resultados desta pesquisa compreenda-se a ação da vitamina D no tratamento e prevenção da COVID-19, assim analisar os meios necessários para evitar a infecção ou agravamento da doença, auxiliando uma melhora na qualidade de vida para a população durante e após a pandemia.

Uma vez que o vírus da COVID-19 emerge, propaga-se rapidamente, e induz doenças infecciosas graves, tornandose uma ameaça contínua. Especialmente quando não há vacinas disponíveis ou medicamentos aprovados para o tratamento.

Nos últimos anos, foram descobertos profundos conhecimentos sobre a resposta imunológica inata. Este tipo de resposta imunológica inibe a replicação do vírus, promove a eliminação, induz a reparação de tecidos e desencadeia uma resposta imunológica adaptativa prolongada contra os vírus.

$\mathrm{Na}$ maioria dos casos, as respostas inflamatórias pulmonares e sistêmicas associadas ao COVID-19 são desencadeadas pelo sistema imune inato quando reconhece o vírus. Embora a vacina seja amplamente protetora, no momento em que essa revisão está sendo feita a grande maioria da população não possui estimativa de ser vacinado tão cedo, portanto fortalecer o sistema de imunológico não deixa ser útil como forma de prevenção e garantia de segurança até que toda a população seja vacinada.

\subsection{Divulgação dos Resultados}

A divulgação dos resultados do projeto será feita através de publicações em revistas científicas e em eventos científicos.

\subsection{Orçamento}

\begin{tabular}{|c|c|c|c|}
\hline Produto & Quantidade & Valor Unitário (R\$) & Valor Total (R\$) \\
\hline Computador & 1 & $1.300,00$ & $1.300,00$ \\
\hline Publicação & 1 & 300,00 & 300,00 \\
\hline \multicolumn{3}{|c|}{ TOTAL } & $\mathbf{1 . 6 0 0 , 0 0}$ \\
\hline
\end{tabular}

Fonte: Autores.

\subsection{Cronograma}

\begin{tabular}{|l|l|l|l|l|l|l|l|}
\hline ATIVIDADES/PERIODOS (2021) & JUN & JUL & AGO & SET & OUT & NOV & DEZ \\
\hline Coleta dos Dados & & & $\mathbf{X}$ & $\mathbf{X}$ & & & \\
\hline Análise e interpretação das informações & & & & & $\mathbf{X}$ & $\mathbf{X}$ & \\
\hline Apresentação de trabalhos em eventos & & & & & & $\mathbf{X}$ & $\mathbf{X}$ \\
\hline $\begin{array}{l}\text { Elaboração e envio de artigos científicos a } \\
\text { periódicos }\end{array}$ & & & & & & $\mathbf{X}$ \\
\hline
\end{tabular}

Fonte: Autores. 


\section{Conclusão}

Para satisfazer as necessidades atuais, devemos propor medidas terapêuticas eficazes utilizando o conhecimento acumulado do sistema imune inato. A imunoterapia orientada é uma boa alternativa a alguns antivirais que têm janelas de tratamento estreitas e se deparam facilmente com a resistência aos medicamentos. Diante disso, e de todas as informações analisadas no referencial teórico, é esperado que a vitamina D seja vista como um método de prevenção alternativo, deixando claro que isso não significa que ela substitua de alguma forma a vacina, mas sim que auxilie no combate ao vírus.

\section{Referências}

Maeda, S. S. Borba, V. Z. C. Camargo, M. B. R. Silva, D. M. W. Borges, J. L. C. Bandeira, F. Castro, M. L. (2014). Recomendações da Sociedade Brasileira de Endocrinologia e Metabologia (SBEM) para o diagnóstico e tratamento da hipovitaminose D. Arquivos Brasileiros de Endocrinologia \& Metabologia. https://doi.org/10.1590/0004-2730000003388

Holick, M. F. (2017). The vitamin D deficiency pandemic: approaches for diagnosis, treatment and prevention. Rev Endocr Metab Disord. 153-165. https://doi.org/10.1007/s11154-017-9424-1

Sadeghian, M.; Saneei, P.; Siassi, F.; Esmaillzadeh, A. (2016). Vitamin D status in relation to Crohn's disease: Meta-analysis of observational studies. Nutrition. 505-514. https://doi.org/10.1016/j.nut.2015.11.008

Gunasekar, P.; Swier, V.J.; Fleegel, J. P.; Boosani, C. S.; Radwan, M. M.; Agrawal, D. K.2018). Vitamin D and macrophage polarization in epicardial adipose tissue of atherosclerotic swine. 13. https://doi.org/10.1371/journal.pone.0199411

Amrein, K.; Quraishi, S. A.; Litonjua, A. A.; Gibbons, F. K.; Pieber, T. R.; Camargo, C. A.; Giovannucci, E.; Christopher, K. B. (2014). Evidence for a Ushaped relationship between prehospital vitamin D status and mortality: A cohort study. J. Clin. Endocrinol. Metab. $1461-1469$. https://doi.org/10.1210/jc.2013-3481

Van, S. N. M., Lips, P. (2011). Worldwide vitamin D status. Best Practice \& Research Clinical Endocrinology \& Metabolism. 1-80. https://doi.org/10.1016/j.beem.2011.06.007

Cashman, K. D., Dowling, K. G., Škrabáková, Z. (2016). Vitamin D deficiency in Europe: pandemic? 1033-1044. https://doi.org/10.3945/ajcn.115.120873

Brown, R. (2020). Preventing a covid-19 pandemic BMJ; 368 https://doi.org/10.1136/bmj.m810

Chakhtoura, M. (2020). Commentary: Myths and facts on vitamin D amidst the COVID-19 pandemic Metabolism. 154-276. https://doi.org/10.1016/j.metabol.2020.154276

Robb, C. T., Regan, K. H, Dorward, D. A, Rossi, A. G. (2016). Key mechanisms governing resolution of lung inflammation. Semin Immunopathol. 25-48. https://doi.org/10.1007/s0. 0281-016-0560-6

Vanherwegen, A. S. (2017) Regulation of Immune Function by Vitamin D and Its Use in Diseases of Immunity Endocrinol Metab Clin North Am;46(4):1061-1094. https://doi.org/10.1016/j.ecl.2017.07.010

Cecere, T. E., Todd, S. M., Leroith, T. (2012). Regulatory T cells in arterivirus and coronavirus infections: do they protect against disease or enhance it?. 4(5):833-846. https://dx.doi.org/10.3390\%2Fv4050833

Maloir, Q., Ghysen, K., Von, Frenckell, C, Louis R, Guiot J. (2018). [Acute respiratory distress revealing antisynthetase syndrome]. Rev Med Liege. 73(78):370-375. https://pubmed.ncbi.nlm.nih.gov/30113776/

Lang, P. O. (2017). Vitamin D Status and the Host Resistance to Infections: What It Is Currently (Not) Understood Clin Ther . 39(5):930-945. https://doi.org/10.1016/j.clinthera.2017.04.004

Li, G.; Fan, Y.; Lai, Y.; Han, T.; Li, Z.; Zhou, P.; Pan, P.; Wang, W.; Hu, D.; Liu, X.; (2020) Coronavirus infections and immune responses. J. Med. Virol. 92, 424-432. https://doi.org/10.1002/jmv.25685

McGonagle, D.; Sharif, K.; O’Regan, A.; Bridgewood, C. (2020) The Role of Cytokines including Interleukin-6 in COVID-19 induced Pneumonia and Macrophage Activation Syndrome-Like Disease Autoimmun. https://doi.org/10.1016/j.autrev.2020.102537

Xu, P.; Zhou, Q.; Xu, J. Mechanism of thrombocytopenia in COVID-19 patients. Ann.Hematol. 1-4. https://dx.doi.org/10.1007\%2Fs00277-020-04019-0

Gruber-Bzura, B. M. (2018). Vitamin D and Influenza-Prevention or Therapy? Int J Mol Sci. 16;19(8):2419. https://doi.org/10.3390/ijms19082419

Bruce D., Ooi J. H., Yu, S., Cantorna M. T. (2010). Vitamin D and host resistance to infection? Putting the cart in front of the horse. Exp. Biol. Med. 235:921-927. https://doi.org/10.1258/ebm.2010.010061

Sharifi, A.; Vahedi, H.; Nedjat, S.; Rafiei, H.; Hosseinzadeh-Attar, M. J. (2019) Effect of single-dose injection of vitamin D on immune cytokines in ulcerative colitis patients: A randomized placebo-controlled trial. 127, 681- 687. https://doi.org/10.1111/apm.12982

Jeffery, L. E.; Burke, F.; Mura, M.; Zheng, Y.; Qureshi, O. S.; Hewison, M.; Walker, L. S.; Lammas, D. A.; Raza, K.; Sansom, D. M. (2009) 1,25- 
Research, Society and Development, v. 10, n. 13, e12101320883, 2021

(CC BY 4.0) | ISSN 2525-3409 | DOI: http://dx.doi.org/10.33448/rsd-v10i13.20883

Dihydroxyvitamin D3 and IL-2 combine to inhibit T cell production of inflammatory cytokines and promote development of regulatory Tcells expressing CTLA-4 and FoxP3. J. Immunol. 183, 5458-5467. https://doi.org/10.4049/jimmunol.0803217

Gombart, A. F.; Pierre, A.; Maggini, S. (2020). A Review of Micronutrients and the Immune System- Working in Harmony to Reduce the Risk of Infection. Nutrients. 12, 236. https://doi.org/10.3390/nu12010236

Loeb, M. (2019). Effect of Vitamin D supplementation to reduce respiratory infections in children and adolescents in Vietnam: a randomized controlled trial Influenza Other Respir. Viruses, pp. 176-183. https://doi.org/10.1111/irv.12615

Daneshkhah, A. (2020). The Possible Role of Vitamin D in Suppressing Cytokine Storm and Associated Mortality in COVID-19 Patients Posted. https://doi.org/10.1101/2020.04.08.20058578 